УДК 159.9

DOI: $10.17223 / 17267080 / 62 / 3$

\title{
Д.А. Леонтьев
}

Национальный исследовательский университет «Высшая школа экономики», г. Москва

\section{Саморегуляция, ресурсы и личностный потенциал}

\author{
Исследование выполнено при поддержке РНФ (проект 16-18-10439 \\ «Системно-динамический анализ регуляции деятельности»)
}

\begin{abstract}
Представлены основы современного подхода к объяснению жизнедеятельности человека через призму принщипа саморегулящии. Раскрывается множественность критериев желаемого, выходящая за рамки максимизации положительных эмочий, дается определение психологического и субъективного благополучия, всесторонне проанализировано понятие ресурсов и дана классификаиия их видов, обосновано понятие личностного потенциала как потенциала саморегуляиии и предложены две классификачии видов и форм саморегуляции.
\end{abstract}

Ключевые слова: саморегуляиия; ресурсы; благополучие; перспектива; эмоции; мотивация; психологический капитал; личностный потенциал.

Самым общим контекстом того узла проблем, который обозначен в заглавии настоящей статьи, выступает проблема, которую сравнительно недавно начали обозначать термином «жизнеспособность» (Махнач, 2016) [1]. Речь идет о достаточно традиционном вопросе: «Почему у одних все получается, а у других нет?».

Мы привыкли в нашей культуре к понятию успеха. Но это понятие не вполне адекватно. Критерии успеха чаще внешние, чем внутренние, хотя бывают и внутренние тоже. Успех может быть и случайным, не являться следствием наших усилий, а с другой стороны, можно достичь социального успеха, адаптации к внешним требованиям ценой отказа от главного в себе - «слушайся и будешь в шоколаде». Идя этим путем, можно оказаться «в шоколаде», но при этом потерять что-то очень важное, хоть и менее очевидное при поверхностном взгляде.

Проблема жизнеспособности - более общая, гораздо шире, чем проблема успеха, оцениваемого по социальным критериям. Суть жизни любого живого существа правомерно рассматривать как поддержание динамического равновесия в отношениях с миром, движение от относительно худшего состояния к относительно лучшему. Можно использовать самые разные критерии, чтобы оценивать качество жизни; если она становится постепенно лучше, то мы на правильном пути, и наоборот, траектория неверна, если жизнь становится хуже, если сегодня хуже, чем вчера, а завтра хуже, чем сегодня. Исследования предикторов суицидального поведения 
выявили, что вероятность суицидальных попыток связана не с абсолютно низким качеством жизни, а с резким относительным его ухудшением, хоть и далеко не достигающим «дна», на котором стабильно живут много людей, не помышляющих о самоубийстве (Baumeister, 1991) [2]. Именно динамические тенденции являются решающими.

В нашем столетии психология все больше поворачивается от изучения механизмов самотождественности и линейного детерминизма применительно к психике, личности и жизнедеятельности, представляющих эти процессы по аналогии с предсказуемыми движениями бильярдного шара под действием удара кия, к пониманию их как процессов, которые продолжают меняться в каждой своей точке. Поведение человека - это не просто «дали мотивацию», и человек пошел в заданном направлении. Все гораздо сложнее, и мы должны, как в фантазии Л. Кэрролла, «бежать изо всех сил, чтобы только оставаться на месте». В широком смысле саморегуляция - это универсальный принцип активности живых и квазиживых систем, направляемых целями или другими высшими критериями желательного. Это механизм целесообразной коррекции активности в движении от менее благоприятных к более благоприятным результатам.

\section{Что такое хорошо, и что такое плохо}

Общепризнано, что человек стремится к лучшему. Есть ли какие-то общие объективные критерии, позволяющие понять, что имеется в виду под лучшим? Можно говорить по меньшей мере про три разных критерия того, что значит лучше.

Во-первых, все живое стремится к приятному, т.е. получать положительные эмоции и избегать отрицательных, стремится к счастью или удовлетворению и избеганию неприятностей.

Во-вторых, оно стремится к успешному. Под успешностью можно понимать максимальный контроль над результатами действий. Маленькие дети обычно счастливее, чем взрослые, поскольку их потребности и мечты легче удовлетворить, но они мало контролируют свое счастье, успешность их действий меньше зависит от них самих, а больше от степени благоприятности окружающей среды.

В-третьих, человеку присуще стремление к осмысленному. Ценность определенным событиям и действиям придает то, что они связаны с широким контекстом и отдаленными последствиями, при этом они не обязательно дают максимум удовольствия. Было, в частности, экспериментально показано, что когда в семье появляются дети, уровень субъективного благополучия родителей падает, зато уровень осмысленности возрастает (Baumeister, Vohs, 2002) [3]. Поэтому люди нередко жертвуют благополучием, счастьем и даже порой жизнью ради того смысла, который больше индивидуальной жизни.

Конечно, контроль над действиями и осмысленность значимо нагружены положительным аффектом, и их бывает трудно в исследовани- 
ях разводить, тем не менее они к нему не сводимы, и уже появляются вполне успешные попытки такого экспериментального разведения [4, 5]. Целенаправленная работа по их разведению разворачивается на основе новой методики переживаний в деятельности [6], ряд экспериментальных публикаций находится в процессе подготовки.

Один лишь критерий приятного, максимизации положительных эмоций, благополучия и счастья, лежащий в основе многих философских и житейских вариантов гедонизма, оказывается принципиально неполным. Все хорошее можно свести исключительно к положительным эмоциям, лишь если резко сузить временную и смысловую перспективу и ограничить жизнь только текущим моментом, здесь-и-теперь. В рамках здесь-итеперь действительно решающую роль играет эмоциональный баланс, стремление к активизации положительных эмоций, гедонизму. В этом мотивационные корни наркомании: главное, максимизировать положительные эмоции сию минуту, здесь-и-теперь, а потом хоть трава не расти.

Ошибку исключительной ориентации на эмоциональную оценку демонстрируют классические эксперименты Д. Редельмейера, Дж. Каца и Д. Канемана с пациентами, подвергавшимися колоноскопии, довольно болезненному обследованию прямой кишки [7]. Пациенты с помощью специального ручного устройства фиксировали в режиме реального времени динамику интенсивности неприятных ощущений. Оказалось, что многое зависит от динамики; большую роль играет та интенсивность, на которой обследование завершается. Пациентам двух групп проводили обследование по единой схеме; в контрольной группе оно завершалось на довольно высокой интенсивности неприятных ощущений, а в экспериментальной группе схема была продолжена, и после этого обследование длилось еще несколько дополнительных минут при несколько меньшей интенсивности неприятных ощущений. После завершения обследования пациенты ретроспективно оценивали общую меру неприятных ощущений. Парадоксальным образом пациенты экспериментальной группы оценили свои ощущения как в целом менее неприятные, чем пациенты контрольной, хотя они получили неприятные ощущения того же объема и интенсивности с добавкой. Авторы делают вывод о большом вкладе максимального и конечного значения интенсивности неприятных ощущений для обобщенной ретроспективной оценки.

Гедонисты - это люди, для которых важнее всего положительные эмоции именно потому, что они ориентируются исключительно на «здесьи-теперь». Они субъективно правы именно потому, что игнорируют смысловые контексты и временную перспективу. Благополучие всецело определяется максимумом положительных и минимумом отрицательных эмоций лишь в рамках стоп-кадра здесь-и-теперь. Если ввести более широкую перспективу, все оказывается не совсем так, и описанные эксперименты Д. Редельмейера с соавторами убедительно это демонстрируют.

Различия между сиюминутной гедонистической оценкой и перспективной оценкой находят отражение в разведении таких двух легко смеши- 
ваемых понятий, как «психологическое благополучие» (psychological wellbeing) и «субъективное благополучие» (subjective well-being). Эти схожие понятия исторически появились независимо друг от друга, в разных, хоть и схожих контекстах, и их соотношение представляет собой реальную проблему. Понятие психологического благополучия ввела в 1980-е гг. К. Рифф для обозначения комплекса психологических характеристик, выступающих предпосылками здоровья и счастья. Теоретическая модель и перечень этих характеристик были выстроены автором на основании концепции позитивного душевного здоровья (С. Джурард, М. Яхода и др.), сформулированной в 1970-е гг. в русле гуманистической психологии [8]. Понятие субъективного благополучия ввел в 1970-е гг. для обозначения обобщенной субъективной оценки меры счастья Э. Динер, исходивший из положения о том, что счастье и благополучие определяются исключительно субъективной оценкой, а не объективными предпосылками, и разработавший завоевавшую огромную популярность шкалу удовлетворенности жизнью [9].

Заданный нами выше контекст рассмотрения проблемы позволяет следующим образом определить соотношение между этими двумя конструктами: психологическое благополучие характеризует объективную меру того, насколько человек по своим психологическим характеристикам и способам функционирования близок к оптимальному уровню жизнеспособности, субъективное благополучие выражает восприятие и оценку самим человеком этой меры близости к желаемому.

\section{Между желанием и результатом: мотивация, способности и ресурсы}

Несмотря на всеобщее стремление к благополучию, достигаемые результаты не у всех одинаковы. Кроме общего стремления к хорошему, требуется что-то еще. М.К Мамардашвили [10. С. 531] констатировал отсутствие прямой причинной связи между желанием добра и реальным деланием добра, отмечая необходимость для этого специальных «нравственных мускулов».

Что опосредует успешность стремления к наилучшему? Во-первых, конкретная мотивация. Достаточно давно было доказано, что из общих движущих человеком мотивов не выводится непосредственная мотивация конкретной деятельности, на которую влияют ситуационные факторы, субъективное восприятие этих факторов, атрибутивные схемы, возможные альтернативы и многое другое [11].

Можно говорить отдельно про содержание, интенсивность и качество мотивации. Содержание мотивации - это конкретные потребности и ценности, направленность на реализацию которых задает мотивацию конкретной деятельности. Этот аспект мотивации выдвигался на первый план в теории иерархии базовых потребностей - первой теории мотивации А. Маслоу [12а], а также в теории мотивации А.Н. Леонтьева, подчеркивавшего предметность потребностей. Влияние интенсивности мотивации на деятельность выражает старый закон Йеркса-Додсона [11], который 
описывает зависимость успешности деятельности от интенсивности мотивации. До какого-то уровня рост интенсивности мотивации положительно влияет на деятельность, а потом начинает действовать разрушительно. Наконец, в теории самодерминации Э. Деси и Р. Райана [12] указывается, что важна не столько интенсивность, сколько качество мотивации. Не всякая интенсивная мотивация работает одинаково хорошо, в частности, даже если внешняя мотивация может позволить успешно решать какие-то тактические задачи, на психологическое благополучие она влияет скорее негативно и не помогает человеку лучше себя в этом мире ощущать. Если игнорировать временное измерение, временную перспективу, сводя все к «здесь-и-теперь», преимущества внутренней мотивации перед внешней исчезают. Они возникают, если ввести эту перспективу.

Помимо конкретной мотивации, связь между желанием и результатом опосредуют способности. Трудно сомневаться в их значимости, однако при системном рассмотрении оказывается, что вклад способностей не является определяющим и опосредован другими, прежде всего личностными факторами. Например, интеллект значимо предсказывает академические достижения учащихся, однако самодисциплина предсказывает их еще лучше [13]. Для творческих результатов личность и мотивация важнее, чем креативность [14]. В спорте мы встречаемся как с очень одаренными атлетами, которые, однако, не слишком хорошо справляются со своими способностями и характеризуются большой нестабильностью (например, недавно завершивший карьеру теннисист Марат Сафин), так и с гораздо менее одаренными спортсменами, которые, однако, за счет качеств личности и хорошей саморегуляции выжимают из своих ограниченных возможностей максимум и достигают результатов, сопоставимых с первыми (например, его соперник Николай Давыденко). Способности важны, но важнее способность использовать свои способности.

Более общее понятие, которое используется в этой связи, - это ресурсы. Под понятием «ресурсы» мы будем понимать средства, наличие и достаточность которых способствует достижению цели и поддержанию благополучия, а отсутствие или недостаточность - затрудняет. Для того, у кого нет цели, ничто не служит ресурсом. Можно сказать, что свойство быть ресурсом - это системное качество, приобретаемое некоторыми объектами или индивидуальными особенностями в структуре деятельности, задаваемой мотивом и целью. При этом ресурсы - это не объяснительное понятие, а описательное.

В зависимости от выраженности ресурсов задачи, решаемые субъектом (это могут быть задачи ориентации и самоопределения, задачи достижения поставленных целей или задачи предотвращения неблагоприятных последствий трудной жизненной ситуации [15]), решаются легче или, напротив, труднее. При этом можно различать специфические, узконаправленные ресурсы, имеющие значение лишь для определенного класса стрессовых ситуаций, и универсальные метаресурсы, обладание которыми дает выигрыш в самых разнообразных ситуациях. 
Можно различать по меньшей мере четыре наиболее глобальных класса ресурсов: физиологические ресурсы (например, общее состояние здоровья или тип нервной системы, от которого зависит легкость и физиологическая «цена» мобилизации), психологические ресурсы (особенности личности, характера, способностей, психических процессов), предметноматериальные ресурсы (орудия и другие предметы, служащие «удлинением» функциональных органов индивида и расширяющие его возможности, например, разнообразные средства передвижения, такие как автомобиль, велосипед, самокат, роликовые коньки, ходули и др.) и социальные ресур$c b l$, обнаруживающиеся во взаимодействии с другими людьми (в частности, социальная поддержка, социальный капитал, репутация и др.). Дефицит одних видов ресурсов может компенсироваться за счет других [16].

В свою очередь, в числе психологических, или личностных, ресурсов можно выделить следующие их разновидности [17]:

1. Психологические ресурсы устойчивости. К ним мы относим прежде всего ценностно-смысловые ресурсы, наличие которых дает субъекту чувство опоры и уверенности в себе, устойчивую самооценку и внутреннее право на активность и принятие решений. К основным переменным этой группы, по нашим данным, относятся, в частности, удовлетворенность жизнью, осмысленность жизни, чувство связности (А. Антоновский) и субъективная витальность как диспозиция (Р. Райан, К. Фредерик), а также базовые убеждения (Р. Янофф-Бульман).

2. Психологические ресурсы саморегулящии. К ним мы относим психологические переменные, отражающие устойчивые, но выбранные из ряда альтернатив стратегии саморегуляции как способа построения динамического взаимодействия с обстоятельствами жизни, такие как мера субъективного контроля над ними или зависимости от них, устойчивые ожидания положительных или отрицательных исходов событий, стратегии взаимодействия со сложностью и неопределенностью, гибкость или ригидность целеполагания, характеристики связи усилий с результатами деятельности и др. В числе релевантных переменных можно назвать каузальные ориентации (Э. Деси, Р. Райан), локус контроля (Дж. Роттер), ориентацию на действие / состояние (Ю. Куль), самоэффективность (А. Бандура), толерантность к неопределенности, склонность к риску, поленезависимость, рефлексию, параметры временной перспективы.

Некоторые психологические переменные, такие как оптимизм (Ч. Карвер, М. Шейер, М. Селигман) или жизнестойкость (С. Мадди), проявляют себя одновременно и как ресурсы устойчивости, снижая общую меру уязвимости субъекта для стрессовых ситуаций, и как ресурсы саморегуляции, определяя характер конкретных решений, принимаемых субъектом в процессе взаимодействия с обстоятельствами его жизни.

3. Мотивационные ресурсы, отражающие энергетическое обеспечение действий индивида по преодолению стрессовой ситуации.

4. Инструментальные ресурсы. К ним относятся способности (индивидуальные особенности, предсказывающие легкость и успешность вы- 
полнения того или иного класса задач), выученные (приобретенные) инструментальные навыки и компетенции, например навыки и стереотипы организации операциональной стороны деятельности, а также стереотипные тактики реагирования на те или иные ситуации (в том числе психологические защиты, или механизмы совладания в узком смысле слова).

Особое значение мы придаем универсальным ресурсам саморегуляции. Они во многом компенсируют дефицит ресурсов устойчивости даже в наиболее экстремальных жизненных обстоятельствах. Эта группа ресурсов, в отличие от остальных, основана во многом на переструктурировании системных связей во взаимодействиях с миром и благодаря этому способна превращать в достоинства даже то, что на первый взгляд выглядит очевидным минусом (например, отчаяние, заставляющее отказаться от воспроизведения безуспешных попыток опереться на прошлый опыт [18], пессимизм и недоверие, повышающие тщательность определенных видов деятельности и внимательность к ошибкам [19], травма и другие жизненные обстоятельства, резко ограничивающие возможности субъекта). Все это мобилизует человека на изменение структуры и компенсаторное повышение качества саморегуляции своей жизнедеятельности; так, у определенной категории лиц с ограниченными возможностями здоровья травма парадоксальным образом оказывается ресурсом роста [20]; известно, что ситуации клинической смерти и других околосмертных переживаний, сталкивающих человека с осознанием реальности собственной смерти, приводят к повышению чувства ответственности за свою жизнь и, как следствие, повышению ее качества [21]. Можно привести прямую аналогию с законом экономической жизни, описанным как «ресурсное проклятие» и хорошо известным россиянам на собственном опыте: благоприятная экономическая конъюнктура и изобилие природных ресурсов приводят к снижению качества принимаемых решений, поскольку цена ошибки сравнительно невелика, и напротив, ситуация дефицита ресурсов делает цену ошибки высокой и вынуждает повысить качество саморегуляции. Ранее мы уже сформулировали это правило в виде общего экзистенциального закона: дефицит любого ресурса повышает эффективность его использования [22].

Именно применительно к ресурсам саморегуляции в ряде исследований сотрудников нашей лаборатории было показано, что они сливаются в единый фактор интегральных ресурсов личности [23-25]. Этот фактор напрямую не предсказывает благополучие, но опосредует влияние на него других ресурсов, а также благоприятных и неблагоприятных условий. В частности, в диссертационном исследовании Т.Ю. Ивановой [24] было показано, что личностные ресурсы выполняют несколько важных функций, и все они связаны не с прямым влиянием на благополучие, а с системным. Личностные ресурсы выполняют буферную функцию, уменьшая зависимость психологического благополучия от факторов среды и ситуации: люди с высокими личностными ресурсами склонны не замечать негативного влияния внешней среды, а у людей с низкими существует прямая связь с динамикой негативного влияния на психологическое благополучие. 
Личностные ресурсы выполняют фильтрующую функиию, опосредуя восприятие и оценку субъектом жизненных обстоятельств: люди с высокими и низкими личностными ресурсами по-разному относятся к требованиям на работе и в профессиональной деятельности. Личностные ресурсы выполняют мотиващионную функцию, способствуя восприятию рабочих ресурсов как более доступных, а рабочих требований - как предметных задач, а не угрозы благополучию.

\section{От личностных ресурсов к личностному потенциалу}

Понятие ресурсов заимствовано из экономического контекста. Другой взаимосвязанной с ним экономической метафорой, описывающей интересующие нас закономерности, является метафора психологического капитала. Это понятие введено по аналогии с категорией капитала в экономике и с появившимися в последние десятилетия в науках о культуре и обществе понятиями «социальный капитал» и «символический капитал» (П. Бурдье).

Одна трактовка психологического капитала, получившая в последние годы заметное распространение и популярность в организационном контексте, вводит понятие психологического капитала в прикладном контексте проблемы позитивного организационного поведения как ответ на вопрос о том, по каким критериям и достоинствам следует в первую очередь проверять и отбирать персонал для успешно работающих организаций [26]. Психологический капитал определяется в этом подходе операционально, как позитивное психологическое состояние развития, характеризующееся: 1) уверенностью в себе, или самоэффективностью, позволяющей прикладывать необходимые усилия для решения сложной задачи; 2) оптимизмом как позитивной атрибуцией текущих и будущих успехов; 3) надеждой как упорством в стремлении к цели вкупе со способностью менять ведущие к ней пути и 4) резилентностью, т.е. упругой устойчивостью к воздействию неблагоприятных обстоятельств [26. Р. 3]. Авторы разработали опросник для диагностики психологического капитала, включающий четыре соответствующих шкалы; хотя они подчеркивают, что психологический капитал как целое не сводится к сумме четырех его составляющих и представляет собой объяснительный конструкт более высокого порядка, чем просто очередной набор компетенций [26. Р. 19], в чем конкретно это проявляется, остается неясным. Хотя авторы сводят к минимуму теоретическое обоснование и осмысление своей модели, на уровне конкретных составляющих модель психологического капитала Ф. Лютанса с соавторами очень близка модели личностного потенциала.

Другое, менее популярное, но более, на наш взгляд, глубокое понимание психологического капитала введено М. Чиксентмихайи [27, 28]. Его трактовка основана на идее ограниченного запаса психической энергии, которая, как и любые ресурсы, может «инвестироваться» в одни или другие виды деятельности, способные обеспечивать либо непосредственное 
удовлетворение, либо отсроченные выгоды, а может и «проматываться», не принося ни удовольствия, ни пользы. Пользу Чиксентмихайи в этом контексте рассматривает прежде всего в терминах развития навыков и повышения внутренней сложности. Примером занятий, ведущих к этому, могут служить благотворительная активность, спорт, творчество. Ресурсы внимания и психической энергии, вкладываемые в подобные занятия, обернутся в будущем прибылью, в то время как вложение их в занятия, приносящие непосредственные положительные эмоции, приведет к их потере. Ресурсы, вкладываемые в воспитание ребенка, превратятся в его социальный капитал и облегчат формирование его психологического капитала. При этом Чиксентмихайи подчеркивает, что речь не идет об «отсрочке удовлетворения» в духе протестантской этики; напротив, важно, чтобы занятия, способствующие формированию психологического капитала в терминах овладения более сложными умениями, несли в себе позитивные эмоции, но при этом требовали приложения усилий [27. Р. 79-80].

Эта модель дополняет и развивает концепцию истощения эго Р. Баумайстера: саморегуляция представляет собой энергозатратный процесс, запас энергии тратится и на физическую, и на психологическую активность [29]. Чиксентмихайи показал, что мы сами по-разному можем управлять этой энергией. Внимание он рассматривает как главный компонент психологического капитала, который позволяет нам перенаправлять энергетические потоки на разные виды деятельности, не просто механически затрачивать энергию на решение задач, но самим управлять этим процессом.

Капитал как экономическая категория обозначает ресурсы, которые вкладываются, принося прибыль, но сами не расходуются. У нас не становится меньше резилентности, меньше самоэффективности или меньше управления вниманием; наоборот, все эти ресурсы умножаются. Но где в этой модели инвестор, тот, кто управляет капиталом? Ресурсы сами себя ни во что не вкладывают. Вспомним библейскую притчу о двух рабах: один вложил свой ресурс (талант) в оборот, другой зарыл в землю. Эта притча говорит нам, что неважно, сколько у тебя ресурсов; если ты не знаешь, как ими пользоваться, их никогда не будет достаточно.

Ответ на этот вопрос позволяет дать понятие личностного потенциала как потенциала саморегуляции [30]. В отличие от термина «капитал» термин «потенциал» - это физико-энергетическая метафора, смысл которой связан с физическим понятием потенциальной энергии как потенциальной способности тела выполнять работу. Понятия этого ряда в психологии предлагались В.М. Бехтеревым (самодеятельность), 3. Фрейдом (работа бессознательного), П. Жане (работа личности), Ф.Е. Василюком (работа переживания) и др. Речь идет именно о работе саморегуляции, о процессах, которые разворачиваются после того, как мотивация сыграла свою роль, дав деятельности начальный толчок. Мы получили толчок и что-то начали делать, а дальше многое зависит от личностного потенциала саморегуляции. По сути, понятие личностного потенциала описывает систему индивидуальных различий, связанных с эффективностью управления энер- 
гетикой. Эволюционная тенденция к росту этой эффективности описана, в частности, в богатой по своим эвристическим возможностям теории энергоэволюционизма М.И. Веллера [31]. Хотя в современной психологии язык энергетических процессов не пользуется популярностью, возможно, разработка концепции личностного потенциала может вдохнуть в этот старый подход новую жизнь.

\section{Принцип саморегуляции как альтернатива идее линейной причинности}

Идея саморегуляции исторически возникла как альтернатива идее линейной причинности, предполагавшей, что любое наше действие где-то начинается и где-то кончается. Н.А. Бернштейн ввел принцип рефлекторного кольца как оппозицию идее рефлекторной дуги Павлова, у которого рефлекс имеет начало и конец. Бернштейн показал, что это бесконечный циклический процесс, который построен так, что на каждом шаге происходит оценка того, насколько то, что получается, близко к тому, чего нам бы хотелось, и внес необходимые коррективы в этот процесс для его оптимизации. Позднее эта модель саморегуляции получила известность благодаря работам Норберта Винера и его соавторов [32, 33]. В центре парадигмы саморегуляции находится идея непрерывных целесообразных изменений. Саморегуляция - это то, что срабатывает, когда не удается уйти от необходимости изменений в деятельности и личности. Ключевой момент механизмов саморегуляции - отрицательная обратная связь, т.е. сигналы об отклонении действительного от желаемого, что помогает нам не принимать желаемое за действительное. Положительная обратная связь - это отождествление желаемого и действительного, сигнал о том, что все в порядке, ничего не надо менять, можно продолжать в том же духе. По сравнению с реакцией на успех реакция на неудачу, на отклонение от цели обнаруживает гораздо больший диапазон и имеет гораздо больше последствий. Это основа любого развития, обучения, целесообразной активности всего живого.

Личностный потенциал помогает осуществлять необходимые изменения, когда они должны быть осуществлены. В этом случае наша система будет продолжать совершенствоваться до естественного исчерпания ее физиологических ресурсов в виде старости и смерти. Есть определенные психологические характеристики, которые с этим связаны: активность, продуктивность, субъектность, резилентность, продуктивное совладание, самодетерминация, целенаправленность, гибкость. Плохая саморегуляция приводит к саморазрушению системы при достаточных физиологических ресурсах, когда система начинает действовать себе во вред, тратить ресурсы впустую. Мы обнаруживаем в этом случае такие признаки системы, как зависимость, конформность, уязвимость, виктимность, непродуктивность, ригидность. Эти два глобальных паттерна можно соотнести с такими конструктами, как антихрупкость и хрупкость (Талеб, 2014) [34]. Люди с низ- 
ким личностным потенциалом, характеризующиеся хрупкостью, тоже могут быть успешны, но платят за это высокую цену - они не могут быть успешны и счастливы одновременно. Либо они отказываются от успеха и радуются жизни, либо достигают успехов, истощая свои ресурсы.

Формы и уровни саморегуляции постоянно усложняются в ходе филогенетической и онтогенетической эволюции [32].

Самая простая из них - самоконтроль, т.е. торможение, блокирование непосредственных импульсивных реакций на внешние и внутренние раздражители. Взрослый человек обладает способностью, хоть и ограниченной, сказать «нет» своим потребностям [35]. Следующая форма - самодисциплина: отсрочка и, в более общем виде, планирование действий во времени. Для того чтобы осуществить переход от способности к самоконтролю и самодисциплине, нужна временная перспектива, способность к антиципации будущих событий, которая формируется постепенно в процессе развития. Третий уровень - самоуправление. Чтобы перейти от самодисциплины к самоуправлению и к регуляции поставленных целей, требуется толерантность к неопределенности, т.е. готовность реагировать на непредсказуемые внешние изменения за рамками принятых заранее планов и поставленных целей, менять цели и намерения, иными словами, готовность действовать в условиях, которые заранее не предопределены. Четвертый уровень - самодетерминация, способность самому ставить себе цели и определять направление своей деятельности. Наконец, на самом высшем уровне мы говорим о самоорганизации. Это качественные изменения системы в целом, связанные с повышением уровня ее сложности и организованности.

Кроме эволюционной классификации по уровням сложности, виды саморегуляции можно классифицировать на основании разных критериев желаемого, которые лежат в основе оценки текущего положения дел [33]. Так, в 1980-е гг. была дискуссия М. Чиксентмихайи и Дж. Накамуры с Ч. Карвером и М. Шейером [30]. Карвер и Шейер в своей обобщенной модели саморегуляции поведения, опирающейся непосредственно на работы Н. Винера, вслед за Винером рассматривали в качестве критерия желаемого цели, преследуемые индивидом; М. Чиксентмихайи и Дж. Накамура не соглашались с принятием целей в качестве такого высшего критерия и обосновывали бо́льшую адекватность другого критерия - позитивных переживаний. Представляется вполне очевидным, что ни один из этих ответов не подходит в качестве универсального, напротив, оба они могут быть верными в конкретных случаях. Возможны и другие варианты критериев регуляции.

1. Первой разновидностью саморегуляции по этому основанию можно считать функциональную саморегуляцию. Сюда мы относим и текущую саморегуляцию функциональных состояний, и более развернутую во времени саморегуляцию функционирования организма в целом, включая вопросы здорового образа жизни. Желательным критерием хорошего функционирования и успешности функциональной саморегуляции высту- 
пает сбалансированность телесных и психических процессов и подсистем организма, проявляющаяся в целом ряде признаков, как объективных (антропометрические показатели, заболеваемость), так и субъективных (самочувствие).

2. Второй столь же хорошо изученной разновидностью саморегуляции выступает целевая саморегуляция. Критерием желаемого выступает цель, а регулируемым процессом - деятельность по ее достижению. Помимо уже упомянутой концепции Ч. Карвера и М. Шейера, к концепциям целевой саморегуляции относится и концепция осознанной саморегуляции О.А. Конопкина и В.И. Моросановой. Вместе с тем соотношение достижения целей и психологического благополучия, как показывают исследования последнего времени, неоднозначны, что свидетельствует об ограниченности моделей целевой саморегуляции. Многое зависит от специфики целей, их качества и связей с мотивацией. Так, например, успешное достижение внешне мотивированных целей, не связанных с собственным Я субъекта, не приводит к повышению благополучия, в отличие от внутренне мотивированных целей [34]. Поэтому целевая саморегуляция неизбежно должна рассматриваться в более общих жизненных контекстах.

3. Отдельной разновидностью интересующих нас процессов выступает эмоциональная саморегуляция, под которой понимается регуляция эмоциональных состояний. Критерием в данном случае является именно субъективное переживание.

4. Мотивационная саморегуляция личности направлена на обеспечение процессов выбора и осуществления субъектом своих мотивов [36]. Далеко не всегда этот процесс может быть редуцирован к достижению цели, а саморегуляция - к целевой. Это критерий более высокого ранга, по отношению к которому функциональные, целевые и эмоциональные критерии служат вспомогательными, более частными.

5. Наиболее общим контуром саморегуляции будет выступать саморегуляция жизнедеятельности в целом, или личностная саморегуляция. Применительно к саморегуляции жизнедеятельности критерием желаемого будет выступать «внутренняя необходимость жизни личности» [37], а этой внутренней необходимостью, в свою очередь, является «реализация своего пути, своего жизненного замысла» [37. С. 47].

Предложенное различение приводит к пониманию саморегуляции как иерархической системы, образуемой различными взаимосвязанными контурами; по отношению к большинству из них субъект может занимать активную позицию, произвольно выбирая и изменяя критерии желаемого и переключаясь с одной системы на другую. Это не относится, вероятно, только к наиболее общей системе саморегуляции жизнедеятельности, которой подчиняются остальные системы: мотивационной и целевой саморегуляции, с одной стороны, эмоциональной и функциональной - с другой. 


\section{К системно-динамической модели регуляции деятельности}

Сказанное позволяет нам реконструировать путь к тому, чтобы наши действия были приятными, результативными и осмысленными. Удобно представить этот путь в виде последовательности внутренних вопросов и ответов на них.

Первый вопрос - вопрос мотивации: мне это вообще надо? Ответ дается в терминах содержания, интенсивности и качества мотива, связи поставленной или принятой цели с личностью в целом в таких категориях, как личностный смысл, конкордантность или аутентичность. Положительный ответ санкционирует дальнейшее разворачивание деятельности, отрицательный - ее тормозит.

Второй вопрос - насколько вероятным мы считаем успешное достижение желаемого результата. Даже самое сильное желание не приведет к действию, если оно сопровождается убеждением в невозможности достичь желаемого. Начиная с модели ожидаемой ценности Дж. Аткинсона, эта идея получила развитие в целом ряде теорий 1960-1970-х гг., связанных с различными трактовками «конструктов контроля» (Skinner, 1983) [38], т.е. конструируемых субъектом взаимосвязей между элементами деятельности, ее результатов и последствий. Ключевыми объяснительными понятиями выступают ожидание, каузальная атрибуция, локус контроля, выученная беспомощность, атрибутивный стиль, самоэффективность.

Третий вопрос - начинать действовать или подождать? Этот аспект регуляции действия раскрывается в «модели Рубикона» Х. Хекхаузена, Ю. Куля и П. Голвитцера [11] и связан с отношением к неопределенности и принятием риска. Даже когда принципиальное решение принято, ничто не определяет момент перехода к реализации действия, кроме экзистенциального акта внутреннего принятия ответственности за него. Существуют индивидуальные различия в решительности, готовности принять эту ответственность, несмотря на всю сохраняющуюся неопределенность.

Четвертый вопрос - все идет как надо или нет? Для ответа на этот вопрос необходимо разделить желаемое и действительное, преодолеть нарциссизм и увидеть реальность максимально трезво и объективно.

Пятый вопрос - нужно ли и можно ли что-то менять в ходе деятельности? Постановке этого вопроса способствуют такие личностные характеристики, как гибкость, креативность. В случае их дефицита субъект стремится максимально сохранять статус кво, что является симптомом хрупкой организации деятельности [34].

Шестой вопрос - сохраняет ли изначальная цель свою актуальность на очередном этапе деятельности или уже пройденный путь привел к ее пересмотру, цель потеряла свой смысл и лучше бы от нее отказаться и поставить новую цель? Вызов отказа от цели представляет собой важную лакмусовую бумажку индивидуальных различий в саморегуляции [39].

Наконец, седьмой вопрос - не нужно ли пересмотреть ценностные основания своих действий? Возможность такого пересмотра является при- 
знаком автономной субъектности (Harre, 1979) [40]. Действительно, пока я «не могу поступиться принципами», пока я раб предыдущей версии самого себя, я не могу полностью быть субъектом собственных действий.

Приведенная схема не противоречит и во многом повторяет некоторые другие схемы системной регуляции деятельности, например центрирующуюся на мотивационных процессах схему Т.О. Гордеевой [41]. В ней на первый план выдвинуты именно текучие динамические процессы. Из приведенной структурно-динамической модели вытекает, что на каждом шагу мы должны решать задачи гибкой ориентировки, и делая это, мы принимаем на себя ответственность за свою жизнь, за то, чтобы самим определять, что для нас лучше и какой ценой этого достичь. Это перекликается с определением личности как того, что человек может противопоставить внутренним импульсам и внешним давлениям [42]; не просто им следовать, или наоборот, расслабиться, а делать выбор по своему усмотрению. Конечно, легче не принимать ответственность за свою жизнь, а приписать ее генетике, среде, режиму, погоде, другим людям, собственному прошлому, не опосредовать самим собой то, что с нами происходит, действуя, как заводные игрушки. Перед нами всегда стоит выбор: плыть по течению, не задаваясь вопросом об изменениях, или двигаться путем самоуправляемой личности.

Все люди разные, они могут использовать разные стратегии и модели. Существуют устойчивые характеристики разных людей, в которых все одинаково предсказуемы, но есть и другие характеристики, в которых каждый человек не только не равен другим, но иногда не равен и самому себе. Павел Флоренский говорил в свое время, что главное, что делает человека человеком - нарушение логического закона тождества, «я равно я». «Победа над законом тождества - вот что поднимает личность над безжизненной вещью и что делает ее живым центром деятельности» [43. С. 80]. Развивая психологическую науку, мы переходим от общих законов, которые управляют и предсказывают поведение больших выборок, к вызовам возможного, по отношению к которым каждый самоопределяется индивидуально и по-разному в каждый момент времени.

\section{Литература}

1. Махнач А.В. Жизнеспособность человека и семьи: социально-психологическая парадигма. М. : Институт психологии РАН, 2016.

2. Baumeister R. Escaping the Self: Alcoholism, Spirituality, Masochism, and Other Flights from the Burden of Selfhood. Basic Books, 1991

3. Baumeister R.F., Vohs K.D. The pursuit of meaningfulness in life // Handbook of Positive Psychology / eds. by C.R. Snyder, S.J. Lopez. New York : Oxford University Press, 2002. P. 608-617.

4. Baumeister R.F., Vohs K.D., Aaker J.L., Garbinsky E.N. Some Key Differences Between a Happy Life and a Meaningful Life // The Journal of Positive Psychology. 2013. № 8. P. 505-516. 
5. Huta V., Ryan R.M. Pursuing pleasure or virtue: The differential and overlapping wellbeing benefits of hedonic and eudaimonic motives // Journal of Happiness Studies. 2010. № 11. Р. 735-762.

6. Леонтьев Д.А. Переживания, сопровождающие деятельность, и их диагностика // Современная психодиагностика России. Преодоление кризиса : сборник материалов III Всероссийской конференции по психологической диагностике / отв. ред. Н.А. Батурин. Челябинск : Издательский центр ЮУрГУ, 2015. Т. 1. С. 175-179.

7. Redelmeier D., Katz J., Kahneman D. Memories of colonoscopy: a randomized trial // Pain. 2003. № 104 (1-2). P. 187-194.

8. Леонтьев Д.А. Подход через позитивные черты личности: от психологического благополучия к добродетелям и силам характера // Личностный потенциал: структура и диагностика / под ред. Д.А. Леонтьева. М. : Смысл, 2011. С. 76-91.

9. Осин Е.Н., Леонтьев Д.А. Апробация русскоязычных версий двух шкал экспрессоценки субъективного благополучия // Материалы III Всероссийского социологического конгресса. М. : Институт социологии РАН, 2008.

10. Мамардашвили М.К. Психологическая топология пути. М. : РХГИ, 1997.

11. Хекхаузен Х. Мотивация и деятельность. 2-е изд., перераб. М. : Смысл ; СПб. : Питер, 2003.

12. Ryan R.M., Deci E.L. Overview of self-determination theory: an organismic dialectical perspective // Handbook of self-determination research / ed. by E.L. Deci, R.M. Ryan. The University of Rochester Press, 2002. P. 3-33.

12а. Леонтьев Д.А. Самоактуализация как движущая сила личностного развития: историко-критический анализ // Современная психология мотивации / под ред. Д.А. Леонтьева. М. : Смысл, 2002. С. 13-46.

13. Duckworth A.L., Seligman M.E.P. Self-discipline outdoes IQ predicting academic performance in adolescents // Psychological Science. 2005. № 16 (12). P. 939-944.

14. Amabile T.M. Beyond Talent: John Irving and the Passionate Craft of Creativity // American Psychologist. 2001. Vol. 56, № 4. P. 333-336.

15. Леонтьев Д.А. Промежуточные итоги: от идеи к концепции, от переменных к системной модели, от вопросов к новым вопросам // Личностный потенциал: структура и диагностика / под ред. Д.А. Леонтьева. М. : Смысл, 2011. С. 669-675.

16. Леонтьев Д.А. Развитие личности в норме и в затрудненных условиях: вызовы и ресурсы // Культурно-историческая психология. 2014. № 3. С. 97-106.

17. Леонтьев Д.А. Психологические ресурсы преодоления стрессовых ситуаций: к уточнению базовых конструктов // Психология стресса и совладающего поведения в современном российском обществе : материалы II Международной научнопрактической конференции. Кострома, 2010. Т. 2. С. 40-42.

18. Мамардашвили М.К. Лекции о Прусте (психологическая топология пути). М. : Ad Marginem, 1995.

19. Зелигман М. Как стать оптимистом. М. : АСТ, 1994.

20. Александрова Л.А., Лебедева А.А., Леонтьев Д.А. Ресурсы саморегуляции студентов c ограниченными возможностями здоровья как фактор эффективности инклюзивного образования // Личностный ресурс субъекта труда в изменяющейся России : материалы II Международной научно-практической конференции. Кисловодск : СевКавГТУ, 2009. Ч. 2 : Симпозиум «Субъект и личность в психологии саморегуляции». С. 11-16.

21. Леонтьев Д.А. Время как измерение человеческой жизни // Время пути: исследования и размышления / под ред. Р.А. Ахмерова, Е.И. Головахи, Е.Г. Злобиной, А.А. Кроника, Д.А. Леонтьева. Киев : Изд-во Ин-та социологии НАН Украины, 2008. С. 8-36.

22. Леонтьев Д.А. Экзистенциальный смысл суицида: жизнь как выбор // Московский психотерапевтический журнал. 2008. № 4. С. 58-82. 
23. Лебедева А.А. Субъективное благополучие лиц с ограниченными возможностями здоровья : дис. ... канд. психол. наук. М., 2012.

24. Иванова Т.Ю. Функциональная роль личностных ресурсов в обеспечении психологического благополучия : дис. ... канд. психол. наук. М., 2016.

25. Иванова Т.Ю., Леонтьев Д.А., Рассказова Е.И. Функции личностных ресурсов в ситуации экономического кризиса // Психология : журнал высшей школы экономики. 2016. Т. 13, № 2. С. 323-346.

26. Luthans F., Youssef C.M., Avolio B.J. Psychological Capital: Developing the Human Competitive Edge. New York : Oxford University Press, 2007.

27. Csikszentmihalyi M. Good Business: Leadership, Flow, and the Making of Meaning. N.Y. : Penguin, 2003.

28. Csikszentmihalyi M. Materialism and the evolution of consciousness // Psychology and Consumer Culture: The Struggle for a Good Life in a Materialistic World / eds. by T. Kasser, A.D. Kanner. Washington (DC) : American Psychological Association, 2004. P. 91-106.

29. Baumeister R.F., Bratslavsky E., Muraven M., Tice D.M. Ego depletion: Is the active self a limited resource? // Journal of Personality and Social Psychology. 1998. № 74 (5). P. 1252-1265.

30. Леонтьев Д.А. Личностный потенциал как потенциал саморегуляции // Ученые записки кафедры общей психологии МГУ им. М.В. Ломоносова / под ред. Б.С. Братуся, Е.Е. Соколовой. М. : Смысл, 2006. Вып. 2. С. 85-105.

31. Веллер М.И. Энергоэволюционизм. М. : Астрель, 2011.

32. Леонтьев Д.А. Саморегуляция как предмет изучения и как объяснительный принцип // Психология саморегуляции в XXI в. / под ред. В.И. Моросановой. СПб. ; М. : Нестор-История, 2011. С. 74-89.

33. Леонтьев Д.А. Виды и уровни саморегуляции в психологическом контексте // Личностный ресурс субъекта труда в изменяющейся России : материалы III Международной научно-практической конференции. Кисловодск ; Ставрополь ; Москва, 2013. Ч. 2: Симпозиум «Субъект и личность в психологии саморегуляции». С. 67-70.

33. Моросанова В.И. Психология саморегуляции. М. ; СПб. : Нестор-История, 2012.

34. Леонтьев Д.А., Сучков Д.Д. Постановка и достижение целей как фактор психологического благополучия // Психологические исследования. 2015. Т. 8, № 44. С. 1. URL: http://psystudy.ru

34. Талеб Н.Н. Антихрупкость: как извлечь выгоду из хаоса. М. : КоЛибри, 2014.

35. Франкл В. Человек в поисках смысла / под ред. Л.Я. Гозмана, Д.А. Леонтьева. М. : Прогресс, 1990.

36. Файзуллаев А.А. Мотивационная саморегуляция личности. Ташкент : Фан, 1987.

37. Василюк Ф.Е. Психология переживания: анализ преодоления критических ситуаций. М. : Изд-во Моск. ун-та, 1984.

38. Skinner E.A. A guide to constructs of control // Journal of Personality and Social Psychology. 1996. № 71. P. 549-570.

39. Рассказова Е.И. Психологические факторы выбора и изменения стратегии действия // Психологический журнал. 2016. Т. 37, № 3. С. 39-49.

40. Harre R. Social being: a theory for social psychology. Oxford : Blackwell, 1979.

41. Гордеева T.O. Психология мотивации достижения. 2-е изд. М. : Смысл, 2015.

42. Леонтьев Д.А. Личностное изменение человеческого развития // Вопросы психологии. 2013. № 3. С. 67-80.

43. Флоренский П.А. Столп и утверждение истины (1914). М. : Правда, 1990. Т. 1 (I).

Поступила в редакиию 02.11.2016 г.; принята 22.11.2016 2. 
ЛЕОНТЬЕВ Дмитрий Алексеевич, доктор психологических наук, профессор, заведующий Международной лабораторией позитивной психологии личности и мотивации Национального исследовательского университета «Высшая школа экономики» (Москва, Россия). E-mail: dmleont@gmail.com

\section{AUTOREGULATION, RESOURCES, AND PERSONALITY POTENTIAL}

Siberian journal of psychology, 2016, 62, 18-37. DOI: 10.17223/17267080/62/

Leontiev Dmitry A., National Research University Higher School of Economics (Moscow; Russian Federation). E-mail: dmleont@gmail.com

Keywords: autoregulation (self-regulation); resources; well-being; perspective; emotions; motivation; psychological capital; personality potential.

The paper lays the foundation of contemporary approaches to the explanation of human life activity in the autoregulation (self-regulation) perspective. The author poses the problem of living capacity exceeding the traditional idea of success, and argues for the multiplicity of the criteria of the desirable. At least three of these criteria, which have complicated relationships with each other, are theoretically justified: 1) maximization of positive affects and minimization of negative ones; 2) deliberate action control and control over the goal attainment; 3) meaning-making through the involvement into significant contexts of one's own and others' lives. The first criterion points at the correspondence to human nature, the second one at the degree of personal maturity, and the third one at the presence of perspective and relatedness with other people.

Considering this system of criteria, the paper offers the definition of psychological and subjective well-being as the objective or subjective degree of correspondence between the actual and the desirable state of functioning. In view of the issue of psychological factors that mediate the attainment of the desired outcome the concept of psychological resources is thoroughly analyzed from the systemic-activity viewpoint; the integral nature of psychological resources is highlighted and a classification of their forms offered. The concepts of psychological capital and personality potential are analyzed as different conceptualizations of the integrative autoregulation potential. While the concept of psychological capital is based on the economic metaphor, the concept of personality potential on the physicalenergetic one.

Autoregulation is presented in the paper as a global explanatory framework. At the same time two different classifications of specific ways and forms of autoregulation are offered. The one is based on the distinction of varied criteria of the desirable with which the actual state of affairs is compared; in line with this, the following processes are distinguished: functional autoregulation, goal autoregulation, emotional autoregulation, motivational autoregulation and personality autoregulation. By the complexity of the organization of the corresponding processes the author distinguishes self-control, self-discipline, self-management, selfdetermination and self-organization. Finally, a systemic-activity model of activity unfolding from the initial motivational impulse to its completion is proposed, that depicts human activity as a process that is flexibly controlled at all its stages.

\section{References}

1. Makhnach, A.V. (2016) Zhiznesposobnost' cheloveka $i$ sem'i: sotsial'nopsikhologicheskaya paradigm [The viability of the person and family: A social and psychological paradigm]. Moscow: Institute of Psychology RAS.

2. Baumeister, R. (1991) Escaping the Self: Alcoholism, Spirituality, Masochism, and Other Flights from the Burden of Selfhood. New York: Basic Books. 
3. Baumeister, R.F. \& Vohs, K.D. (2002) The pursuit of meaningfulness in life. In: Snyder, C.R. \& Lopez, S.J. (eds). Handbook of Positive Psychology. New York: Oxford University Press. pp. 608-617.

4. Baumeister, R.F., Vohs, K.D., Aaker, J.L. \& Garbinsky, E.N. (2013) Some Key Differences Between a Happy Life and a Meaningful Life. The Journal of Positive Psychology. 8. pp. 505-516. DOI: $10.2139 /$ ssrn. 2168436

5. Huta, V. \& Ryan, R.M. (2010) Pursuing pleasure or virtue: The differential and overlapping well-being benefits of hedonic and eudaimonic motives. Journal of Happiness Studies. 11. pp. 735-762. DOI: 10.1007/s10902-009-9171-4

6. Leontiev, D.A. (2015) Perezhivaniya, soprovozhdayushchie deyatel'nost', i ikh diagnostika [Experiences of accompanying activities and their diagnostics]. In: Baturin, N.A. (ed.) Sovremennaya psikhodiagnostika Rossii. Preodolenie krizisa [Modern psychodiagnostics in Russia. Overcoming the crisis]. Vol. 1. Chelyabinsk: South Urals State University. pp. 175-179.

7. Redelmeier, D., Katz, J. \& Kahneman, D. (2003) Memories of colonoscopy: a randomized trial. Pain. 104(1-2). pp. 187-194. DOI: 10.1016/S0304-3959(03)00003-4

8. Leontiev, D.A. (2011) Podkhod cherez pozitivnye cherty lichnosti: ot psikhologicheskogo blagopoluchiya $\mathrm{k}$ dobrodetelyam i silam kharaktera [The approach through positive personality traits: from the psychological well-being to the virtues and the forces of character]. In: Leontiev, D.A. (ed.) Lichnostnyy potentsial: struktura i diagnostika [Personal Potential: Structure and diagnostics]. Moscow: Smysl. pp. 76-91.

9. Osin, E.N. \& Leontiev, D.A. (2008) Aprobatsiya russkoyazychnykh versiy dvukh shkal ekspress-otsenki sub"ektivnogo blagopoluchiya [Validation of Russian versions of the two scales of a rapid assessment of subjective well-being]. In: Materialy III Vserossiyskogo sotsiologicheskogo kongressa [Proceedings of the Third All-Russian Sociological Congress]. Moscow: Institute of Sociology, Russian Academy of Sciences.

10. Mamardashvili, M.K. (1997) Psikhologicheskaya topologiya puti [Psychological topology of the way]. Moscow: Russian Christian Institute for the Humanities.

11. Hekhauzen, H. (2003) Motivatsiya i deyatel'nost' [Motivation and Action]. Translated from German. 2nd ed. Moscow: Smysl; St. Petersburg: Piter.

12. Ryan, R.M. \& Deci, E.L. (2002) Overview of self-determination theory: an organismic dialectical perspective. In: Deci, E.L. \& Ryan, R.M. (eds) Handbook of self-determination research. University of Rochester Press. pp. 3-33.

12a. Leontiev, D.A. (2002) Samoaktualizatsiya kak dvizhushchaya sila lichnostnogo razvitiya: istoriko-kriticheskiy analiz [Self-actualization as a driving force of personality development: historical and critical analysis]. In: Leontiev, D.A. (ed.) Sovremennaya psikhologiya motivatsii [Modern psychology of motivation]. Moscow: Smysl. pp. 13-46.

13. Duckworth, A.L. \& Seligman, M.E.P. (2005) Self-discipline outdoes IQ predicting academic performance in adolescents. Psychological Science. 16(12). pp. 939-944. DOI: 10.1111/j.1467-9280.2005.01641.x

14. Amabile, T.M. (2001) Beyond Talent: John Irving and the Passionate Craft of Creativity. American Psychologist. 56(4). pp. 333-336. DOI: 10.1037//0003-066X.56.4.333

15. Leontiev, D.A. (2011) Promezhutochnye itogi: ot idei k kontseptsii, ot peremennykh k sistemnoy modeli, ot voprosov k novym voprosam [Interim results: From the idea to the concept, the variables to the system model, from issues to new issues]. In: Leontiev, D.A. (ed.) Lichnostnyy potentsial: struktura i diagnostika [Personal Potential: Structure and diagnostics]. Moscow: Smysl. pp. 669-675.

16. Leontiev, D.A. (2014) Razvitie lichnosti v norme i v zatrudnennykh usloviyakh: vyzovy i resursy [Development of the person in norm and under difficult conditions: challenges and resources]. Kul'turno-istoricheskaya psikhologiya. 3. pp. 97-106.

17. Leontiev, D.A. (2010) [Psychological resources to overcome stressful situations: Clarifying the basic constructs]. Psikhologiya stressa $i$ sovladayushchego povedeniya $v$ sovremennom rossiyskom obshchestve [Psychology of Stress and Coping Behavior in the 
Modern Russian Society]. Proc. of the Second International Conference. Vol. 2. Kostroma. pp. 40-42. (In Russian).

18. Mamardashvili, M.K. (1995) Lektsii o Pruste (psikhologicheskaya topologiya puti) [Lectures on Proust (Psychological topology of the way)]. Moscow: Ad Marginem.

19. Seligman, M. (1994) Kak stat' optimistom [How to become an optimist]. Translated from English. Moscow: AST.

20. Aleksandrova, L.A., Lebedeva, A.A. \& Leontiev, D.A. (2009) [Resources for the selfregulation of students with disabilities as a factor in inclusive education effectiveness]. Lichnostnyy resurs sub"ekta truda $v$ izmenyayushcheysya Rossii [Personal resources of the subject in a changing Russia]. Proc. of the Second International Conference. Kislovodsk. pp. 11-16. (In Russian).

21. Leontiev, D.A. (2008) Vremya kak izmerenie chelovecheskoy zhizni [Time as a dimension of human life]. In: Akhmerov, R.A., Golovakha, E.I., Zlobina, E.G., Kronik, A.A. \& Leontiev, D.A. (eds) Vremya puti: issledovaniya i razmyshleniya [Time of the way: A study and reflection]. Kiev: Institute of Sociology of NAS of Ukraine. pp. 8-36.

22. Leontiev, D.A. (2008) Ekzistentsial'nyy smysl suitsida: zhizn' kak vybor [The existential meaning of suicide: life as a choice]. Moskovskiy psikhoterapevticheskiy zhurnal. 4. pp. $58-82$.

23. Lebedeva, A.A. (2012) Sub"ektivnoe blagopoluchie lits s ogranichennymi vozmozhnostyami zdorov'ya [Subjective well-being of people with disabilities]. Psychology Cand. Diss. Moscow.

24. Ivanova, T.Yu. (2016) Funktsional'naya rol' lichnostnykh resursov v obespechenii psikhologicheskogo blagopoluchiya [The functional role of personal resources to provide psychological well-being]. Psychology Cand. Diss. Moscow.

25. Ivanova, T.Yu., Leontiev, D.A. \& Rasskazova, E.I. (2016) Functions of Personality Resources in a Situation of Economic Crisis. Psikhologiya. Zhurnal vysshey shkoly ekonomiki - Psychology. Journal of the Higher School of Economics. 13(2). pp. 323-346.

26. Luthans, F., Youssef, C.M. \& Avolio, B.J. (2007) Psychological Capital: Developing the Human Competitive Edge. New York: Oxford University Press.

27. Csikszentmihalyi, M. (2003) Good Business: Leadership, Flow, and the Making of Meaning. New York: Penguin.

28. Csikszentmihalyi, M. (2004) Materialism and the evolution of consciousness. In: Kasser, T. \& Kanner, A.D. (eds). Psychology and Consumer Culture: The Struggle for a Good Life in a Materialistic World. Washington (DC): American Psychological Association. pp. 91-106.

29. Baumeister, R.F., Bratslavsky, E., Muraven, M. \& Tice, D.M. (1998) Ego depletion: Is the active self a limited resource? Journal of Personality and Social Psychology. 74(5). pp. 1252-1265. DOI: 10.1037/0022-3514.74.5.1252

30. Leontiev, D.A. (2006) Lichnostnyy potentsial kak potentsial samoregulyatsii [Personal potential as the potential of self-regulation]. Uchenye zapiski kafedry obshchey psikhologii MGU im. M.V. Lomonosova. 2. pp. 85-105.

31. Veller, M.I. (2011) Energoevolyutsionizm [Energy evolutionism]. Moscow: Astrel'.

32. Leontiev, D.A. (2011) Samoregulyatsiya kak predmet izucheniya i kak ob"yasnitel'nyy printsip [Self-regulation as an object of study and as an explanatory principle]. In: Morosanova, V.I. (ed.) Psikhologiya samoregulyatsii v XXI v. [Psychology of self-regulation in the 21st century]. St. Petersburg; Moscow: Nestor-Istoriya. pp. 74-89.

33. Leontiev, D.A. (2013) [Types and levels of self-regulation in the psychological context]. Lichnostnyy resurs sub"ekta truda $v$ izmenyayushcheysya Rossii [Personal resources of the subject in a changing Russia]. Proc. of the Second International Conference. Kislovodsk. pp. 67-70. (In Russian).

33. Morosanova, V.I. (ed.) (2012) Psikhologiya samoregulyatsii [Psychology of selfregulation]. St. Petersburg; Moscow: Nestor-Istoriya. 
34. Leontiev, D.A. \& Suchkov, D.D. (2015) Postanovka i dostizhenie tseley kak faktor psikhologicheskogo blagopoluchiya [Setting and achieving goals as a factor of psychological wellbeing]. Psikhologicheskie issledovaniya. 8(44). pp. 1.

34. Taleb, N.N. (2014) Antikhrupkost': kak izvlech' vygodu iz khaosa [Antifragility: How to profit from the chaos]. Moscow: KoLibri.

35. Frankl, V. (1990) Chelovek v poiskakh smysla [Man in search of meaning]. Translated from English. Moscow: Progress.

36. Fayzullaev, A.A. (1987) Motivatsionnaya samoregulyatsiya lichnosti [Motivational selfregulation of the individual]. Tashkent: Fan.

37. Vasilyuk, F.E. (1984) Psikhologiya perezhivaniya: analiz preodoleniya kriticheskikh situatsiy [Psychology of experiences: An analysis of overcoming critical situations]. Moscow: Moscow State University.

38. Skinner, E.A. (1996) A guide to constructs of control. Journal of Personality and Social Psychology. 71. pp. 549-570. DOI: 10.1037/0022-3514.71.3.549

39. Rasskazova, E.I. (2016) Psikhologicheskie faktory vybora i izmeneniya strategii deystviya [Psychological factors of choice and change in action strategy]. Psikhologicheskiy zhurnal. 37(3). pp. 39-49.

40. Harre, R. (1979) Social being: a theory for social psychology. Oxford: Blackwell.

41. Gordeeva, T.O. (2015) Psikhologiya motivatsii dostizheniya [Psychology of achievement motivation]. 2nd ed. Moscow: Smysl.

42. Leontiev, D.A. (2013) Lichnostnoe izmenenie chelovecheskogo razvitiya [The personality change in human development]. Voprosy psikhologii. 3. pp. 67-80.

43. Florenskiy, P.A. (1990) Stolp i utverzhdenie istiny (1914) [The pillar and ground of the truth (1914)]. Vol. 1. Moscow: Pravda. 